\title{
The impact of cirrus clouds on tropical troposphere-to-stratosphere transport
}

\author{
T. Corti ${ }^{1}$, B. P. Luo ${ }^{1}$, Q. Fu ${ }^{2}$, H. Vömel ${ }^{3}$, and T. Peter ${ }^{1}$ \\ ${ }^{1}$ Institute for Atmospheric and Climate Science, ETH Zurich, Switzerland \\ ${ }^{2}$ Department of Atmospheric Sciences, University of Washington, Seattle, WA, USA \\ ${ }^{3}$ Cooperative Institute for Research in Environmental Sciences, University of Colorado, Boulder, CO, USA
}

Received: 7 December 2005 - Published in Atmos. Chem. Phys. Discuss.: 9 March 2006

Revised: 29 May 2006 - Accepted: 29 May 2006 - Published: 3 July 2006

\begin{abstract}
Although it is well known that air enters the stratosphere preferentially through upwelling in the tropics, the exact mechanisms of troposphere-to-stratosphere transport (TST) are still unknown. Previously proposed mechanisms have been found either to be too slow (e.g., clear sky upwelling) to provide agreement with in situ tracer measurements, or to be insufficient in mass flux to act as a major supply for the Brewer-Dobson circulation (e.g., convective overshooting). In this study we evaluate whether the lofting of air via cirrus cloud-radiation interaction might offer an alternative path for TST, which is responsible for a significant fraction of the observed air mass transport. We find that a combination of deep convection and subsequent upwelling associated with cirrus clouds and clear sky can explain the supply of air for the Brewer-Dobson circulation. Thus, upwelling associated with cirrus clouds offers a mechanism for the missing second stage, which links the first stage of TST, deep convection, to the third stage, the Brewer-Dobson circulation.
\end{abstract}

\section{Introduction}

Air enters the stratosphere preferentially through upwelling in the tropics. Processes involved with tropical troposphereto-stratosphere transport (TST) therefore determine the composition of the air masses reaching the stratosphere. It is well accepted that air is lifted from the surface into the tropical upper troposphere by convection, driven by latent heat release. How air reaches the tropical cold point tropopause situated at about $380 \mathrm{~K}$ potential temperature is however subject of ongoing research. Due to latent heat release alone, deep convection can reach potential temperatures of typically less than $360 \mathrm{~K}$ (Folkins et al., 2000). The main outflow

Correspondence to: T. Corti

(thierry.corti@env.ethz.ch) of tropical deep convection is found even lower at around $13 \mathrm{~km}$ or $350 \mathrm{~K}$ potential temperature (Folkins and Martin, 2005). Higher potential temperatures can be reached in overshooting events, where convective air masses mix with air of higher potential temperature. There have been observations of convective overshooting turrets (e.g., Kelly et al., 1993), transporting air directly into the lower stratosphere, but these cases seem to be very rare. Furthermore, the mass fluxes involved in such events are most likely far too small to supply the Brewer-Dobson circulation with sufficient mass (Gettelman et al., 2002).

The outflow from most deep convection subsides again due to radiative cooling, which prevails below the so-called "level of zero net radiative heating" $(Q=0)$. In clear sky, this level is situated at $15 \mathrm{~km}$ or $360 \mathrm{~K}$ potential temperature (Gettelman et al., 2004). In full sky, the transition from radiative cooling to heating occurs about $0.5-1.0 \mathrm{~km}$ lower than in clear sky (Corti et al., 2005). The existence of a level of $Q=0$ has led to the general assumption that in order to reach the stratosphere, convection has to transport air at least to $360 \mathrm{~K}$, from where radiative heating continues to lift the air to the cold point tropopause in large scale upwelling. Although the mass fluxes involved in large scale upwelling are large enough to supply the Brewer-Dobson circulation with sufficient air (see e.g., Corti et al., 2005), there is yet another problem. The seasonal cycle of $\mathrm{CO}_{2}$ occurring in the planetary boundary layer can be found with little damping at $390 \mathrm{~K}$ and $420 \mathrm{~K}$ with a time lag of $60 \pm 20$ days and $110 \pm 30$ days, respectively (Boering et al., 1994; Andrews et al., 1999; Sherwood and Dessler, 2003). Sherwood and Dessler have shown that a combination of deep convection reaching close to the level of $Q=0$ with subsequent large scale upwelling in clear sky is too slow to explain the time lag. They concluded that overshooting in very deep convection was needed in order to transport air from the ground to the tropical lower stratosphere in a sufficiently short time. However, observations and cloud resolving models indicate

Published by Copernicus GmbH on behalf of the European Geosciences Union. 
(a)

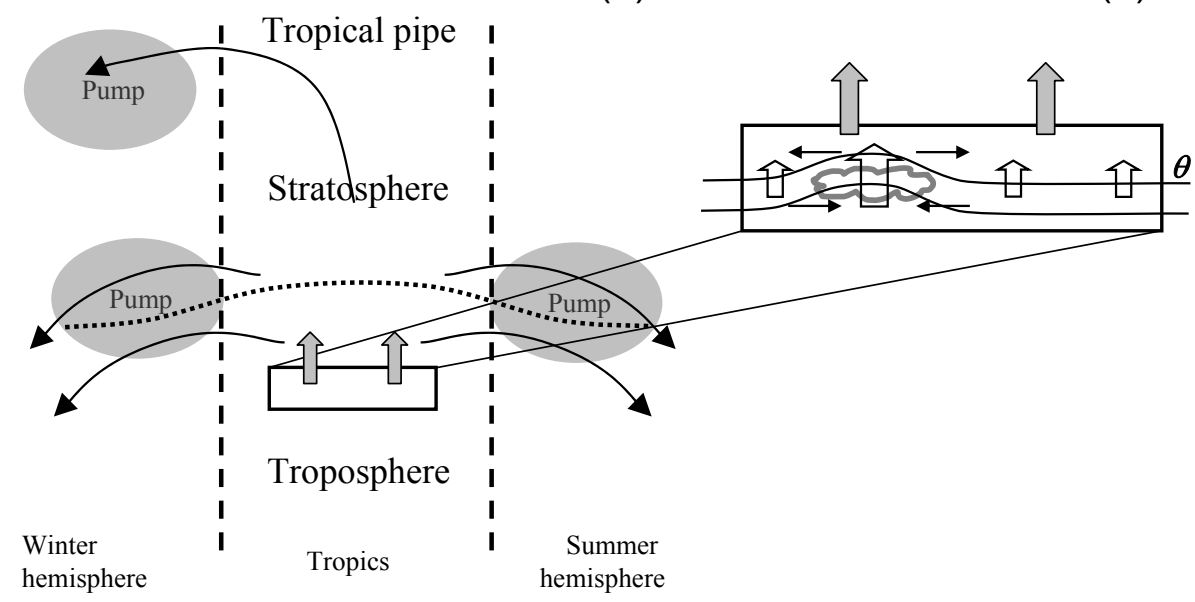

(b)

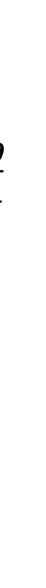

Fig. 1. Schematic of tropical large scale upwelling. (a) The mean transport through the tropical cold point tropopause is mainly driven by dissipating waves (see Plumb, 2002). (b) The mesoscale differences in the upwelling velocity are determined by radiative properties of cloudy and cloud free air masses. Specifically, absorption of infrared radiation in upper tropospheric cirrus leads to enhanced upwelling.

that this transport mechanism is too rare for being responsible for TST (Gettelman et al., 2002; Kupper et al., 2004).

The fact that the transition between the Hadley circulation and the Brewer-Dobson circulation is smooth and that therefore the tropical tropopause is not a material surface has led to the introduction of the tropical tropopause layer (TTL). The TTL is thought as a layer in which the transition from a convectively driven circulation to a wave driven circulation occurs. As there is no commonly accepted definition for the TTL, we will give our own here. We take isentropic surfaces as boundaries, so that air enters or leaves the TTL only due to diabatic processes. For the lower limit of the TTL, we choose the $350 \mathrm{~K}$ isentropic surface, which corresponds to the level of the main convective outflow. The upper limit of the TTL is set to $420 \mathrm{~K}$ potential temperature. This level marks approximately the top of the North-South divergence in the tropical upwelling mass flux (Corti et al., 2005). Moreover, it is thought to be the highest level reached by the deepest convection (e.g., Kelly et al., 1993; Sherwood and Dessler, 2001). All dehydration events most likely occur below that level.

Given that overshooting convection is sufficiently rapid but too rare, and that moderately deep convection is sufficiently frequent but subsequent radiative lifting in clear sky is too slow, we evaluate if the inclusion of cloud radiative effects might offer an alternative path for TST, which is fast and intensive. We first clarify how radiative transport can effectively drive vertical mass transport. Then, we use radiative transfer calculations to quantify upwelling and subsidence in clouds and in cloud free air in the tropical upper troposphere and lower stratosphere (UTLS).

\section{Vertical transport due to radiative processes}

Vertical transport that is defined as the transport across isentropes might be divided into convective transport due to latent or sensible heat release, and radiative transport due to radiative heating or cooling. This classification is justified by the circumstance that latent heat release and in cloud sensible heat transport are the major driving forces in low level clouds and deep convection. In high altitude cirrus clouds on the other hand, radiation is the dominant element for transport across isentropes.

Convection is an undisputed mechanism for vertical transport in the tropics. This is not the case for radiatively driven upwelling. It is broadly acknowledged that air ascends in the tropical upper troposphere and merges into the BrewerDobson circulation. However, this circulation is thought to be driven by dissipating synoptic- and planetary-scale waves (Holton et al., 1995; Plumb, 2002), exerting the effect of a suction pump on the tropical tropopause region (Fig. 1a). Forced by wave dissipation, the upwelling motion leads to advective cooling, lowering the temperature below radiative equilibrium, causing radiative heating which allows the air to readjust its temperature while rising continuously. The mean vertical temperature profile is then determined by the mean radiative properties of the atmosphere. In this picture, known as the "downward control principle" (Haynes et al., 1991), the wave drag is the dominant force, the "Master" of the upwelling, whereas radiation is seen as a purely balancing component, as a "Slave", solely responsible for heating the air. This is why radiation is often believed to play a purely passive role in tropical upwelling.

Although this picture might be largely correct in the stratosphere, the situation could be quite different in the troposphere, where horizontal variability in cloudiness leads 


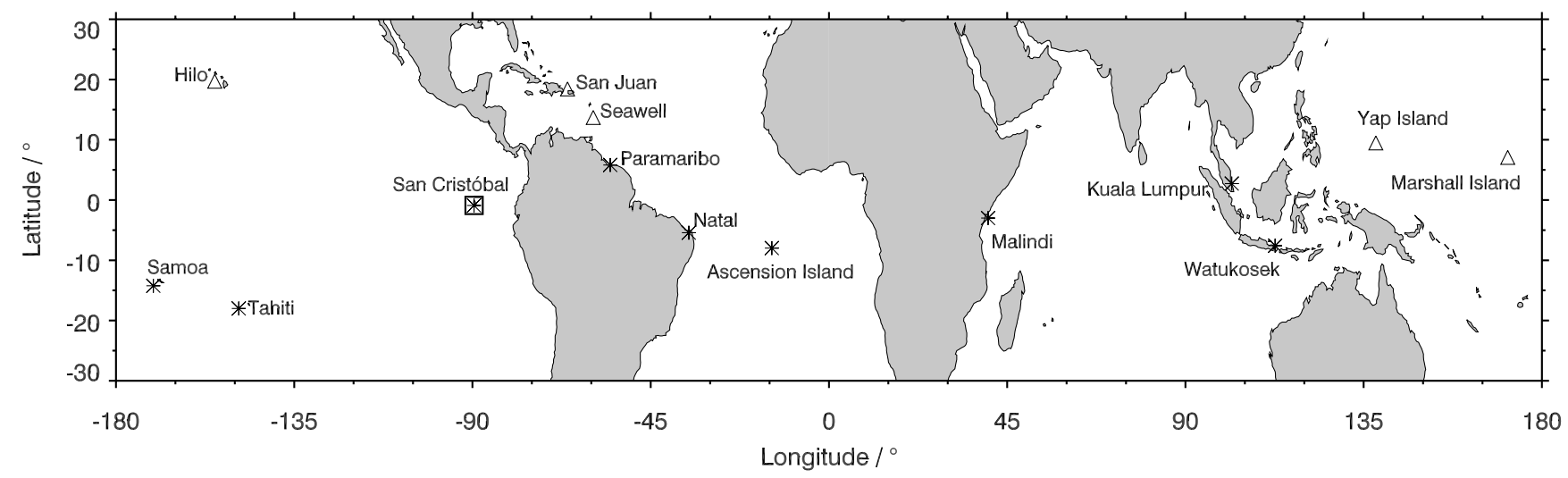

Fig. 2. Locations of tropical $\left(20^{\circ} \mathrm{S}\right.$ to $\left.20^{\circ} \mathrm{N}\right)$ radiosonde measurements used in this study. San Cristóbal (square): simultaneously measured profiles of water vapor, temperature and ozone. Tropical Southern Hemisphere Additional Ozonesondes (SHADOZ) network locations (stars): simultaneously measured temperature and ozone profiles. Tropical NOAA/NCDC radiosonde locations (triangles): high resolution temperature profiles.

to different radiative heating rates on the mesoscale or on the scale of individual air parcels. Specifically, enhanced infrared absorption in thin high altitude cirrus clouds results in higher heating rates, leading to an increase of the potential temperature $(\theta)$ and thus to upward transport of air masses relative to $\theta$ levels. In addition, the enhanced radiative heating results in horizontal gradients of isentropes and geopotential, which lead to a circulation attempting to flatten the horizontal gradients (Fig. 1b). Such dynamic adjustment is very efficient in the tropics, where the coriolis parameter becomes small, keeping horizontal temperature gradients small (Sobel et al., 2001). Therefore, enhanced radiative heating in cirrus clouds translates locally into faster upwelling than in cloud free air. This phenomenon is known as "cloud lofting" and has first been described by Lilly (1988) and Ackerman et al. (1988).

In summary, we argue that the extratropical pump may dominate the large scale background circulation, but that radiation plays an active role in driving the tropical upwelling on the mesoscale. Whether air masses are efficiently transported upward is determined by their cloud radiative properties relative to the environment. Therefore, individual air parcels experience radiative heating, not as a balancing process, but as a forcing that determines the actual diabatic ascent or decent rate of individual air parcels,

$\frac{d \theta}{d t}=Q_{\mathrm{rad}}$,

where $Q_{\text {rad }}$ is the radiative heating rate expressed as potential temperature change per time (Note: $Q_{\text {rad }}$ is defined differently here than in Corti et al. (2005), where it was expressed as temperature change per time). The vertical mass flux $M$ at a certain altitude is then

$M=\rho \frac{d z}{d \theta} Q_{\mathrm{rad}}$,

with $\rho$ being the mass density of air.

\section{Data}

\subsection{Atmospheric profile data}

Balloon sonde measurements from different sources have been evaluated to establish a set of vertical temperature, ozone and water vapor profiles with high vertical resolution. 15 water vapor profiles reaching from the ground up to at least $28 \mathrm{~km}$ altitude were obtained from balloon soundings with a frost point hygrometer during different seasons at San Cristóbal, Galapagos Islands (Vomel et al., 2002). Simultaneously measured temperature and ozone profiles were obtained from soundings at all tropical Southern Hemisphere Additional Ozonesondes (SHADOZ) network locations (Fig. 2) but Nairobi (because this high altitude station seems to show a clear orographic influence of Mt. Kenya on the profiles) (Thompson et al., 2003a,b). All profiles from 1998-2004 without major gaps up to $28 \mathrm{~km}$ were used, adding up to a total of 1554 profiles. In order to obtain a better representation of the Northern Hemisphere in the data set, 15880 vertical temperature profiles measured between 1998 and 2004 were taken from the Stratospheric Processes and their Role in Climate (SPARC) archive of NOAA/NCDC high resolution radiosonde measurements (Fig. 2).

All data has been gridded vertically with a resolution of $250 \mathrm{~m}$. Calculations with the 15 individual water vapor profiles from soundings at San Cristóbal showed that a mean water vapor profile is sufficient for the computation of mean clear sky heating rate profiles in the UTLS (Corti et al., 2005). This is not true in the lower troposphere, where nonlinear effects from water vapor occur. Calculations with profiles from the SHADOZ network locations led to similar results for ozone (i.e., it is not necessary to perform many radiative calculations on all individual profiles and do the averaging afterward, but suffices to average over all atmospheric profiles and do one single calculation). However, 
calculations with individual profiles are indispensable for quantifying heating rate variabilities. Moreover, it needs to be emphasized that the presence of clouds always requires a case-by-case treatment, hence multiplying the number of necessary calculations.

\subsection{Cloud data and method}

Information on cloud occurrence and properties from two sources were combined for this study, the ISCCP D1 data (Rossow and Schiffer, 1999) and cloud observations from LITE (McCormick et al., 1993).

The ISCCP D1 data set provides cloud occurrence statistics from September 1983 to September 2001. It is based on the analysis of radiance measurements from weather satellites with a spatial sampling resolution of approximately $30 \mathrm{~km}$. Every radiance measurement is classified either as clear sky or as containing a single layer cloud with specific cloud top pressure and optical depth. The lack of information on detailed cloud vertical structure is a serious limitation of the ISCCP data for the computation of radiative heating rates. In order to overcome this limitation, we have combined the ISCCP D1 data with measurements from the LITE, a space borne lidar flown on space shuttle Discovery from 10-19 September 1994. A detailed description of the experimental design can be found in McCormick et al. (1993). Winker et al. (1996) have provided an overview on the measurements performed during the experiment.

The standard lidar equation assuming single scattering is insufficient for long-range or wide field-of-view application, where contributions from multiple scattering to the return signal become important. This phenomenon has two aspects. On one hand, the optical depth derived from measurements using the single-scatter assumption can be reduced due to multiple scattering by at least a factor of 2 with respect to the true value (Chepfer et al., 1999). As consequence, a factor $\eta$ has been introduced to take multiple scattering into account, leading to the equation

$S(z)=C \beta(z) \exp (-2 \eta \tau(z))$,

where $S(z)$ is the lidar signal, $C$ an instrumental constant, $\beta$ the backscatter coefficient and $\tau$ the optical depth. Volger et al. (2002) have examined in detail the multiple scattering for LITE, finding $\eta$ to be almost constant in cirrus and water clouds, amounting to 0.4 and 0.6, respectively (In fact, they used an slightly different lidar equation employing a multiple scattering coefficient $F=1-\eta$ ). On the other hand, multiple scattering can lead to lidar pulse stretching within optically thick clouds, which appear in the backscattered profiles as streaks of fading intensity at the cloud bases (Miller and Stephens, 1999). However, pulse stretching becomes significant only in clouds with an optical depth well above unity. As we use exclusively lidar information up to an optical depth of 1.27 (see below), our analysis is not affected by the pulse stretching problem.
The lidar signals were inverted after taking the mean over 10 shots, using Eq. (3), assuming ice clouds above $7 \mathrm{~km}$ and water clouds below. A cloud was defined as every atmospheric feature that created a signal 6 times higher than the noise level in the backscatter ratio profile. For thin clouds with optical depth $\tau$ below $0.1, \tau$ was estimated from the signal using a fixed extinction to backscatter ratio of 40 , which was determined based on the analysis of denser clouds. For denser clouds, the extinction to backscatter ratio was estimated from the signal below the cloud layer. The analysis was constrained to high gain data only, which allows a good characterization of thin high cirrus clouds, resulting in a total number of 21472 extinction profiles. We estimate that a cloud layer of 500-m thickness has a minimum detectable $\tau$ of about $4 \times 10^{-3}$ (Corti et al., 2005). It should be noted that many subvisual clouds were detected by LITE, whereas signals from ultra thin tropical tropopause clouds (UTTC) (Peter et al., 2003; Luo et al., 2003) with optical depth of typically $10^{-4}$ remained below detection limit. Despite its short measurement period of 10 days, LITE provides excellent information in vertical structure of optically thin tropical clouds, shown to be an essential complement to other observations, e.g. cloud top statistics from a ground based micropulse lidar in the tropical western Pacific (Comstock et al., 2002; Corti et al., 2005). Optical depth frequency distributions and mean geometrical thickness agree well with airborne measurements presented in McFarquhar et al. (2000). Also, 56\% of the LITE profiles have optical depth below 1.27 (including clear sky situations), compared to $55 \%$ for the ISCCP data from $20^{\circ} \mathrm{S}$ to $20^{\circ} \mathrm{N}$.

We construct a combined LITE-ISCCP data set in the following way. In all cases with optical depth below 1.27 the complete extinction profiles from LITE were used for the radiative calculations. In all cases with optical depth above 1.27, the LITE extinction profiles were used from the top of the atmosphere down to the altitude where optical depth reached 1.0. There, a cloud was inserted downward according to the occurrence frequency for denser clouds from the ISCCP cloud distribution. The vertical extent of these clouds was set to climatological values (Liou, 1992).

\subsection{Radiative transfer calculation}

The model by Fu and Liou $(1992,1993)$ was used to calculate the radiative heating rates. The single scattering properties of ice water clouds are parameterized with a generalized effective particle size $\left(D_{g e}\right)$ and ice water content based on Fu (1996) and Fu et al. (1998). We assume $D_{g e}=13 \mu \mathrm{m}$ for cirrus clouds, consistent with aircraft observations (McFarquhar et al., 2000). The ice water content was calculated from the cloud extinction and $D_{g e}$, employing the equation presented in Fu (1996), which assures consistency with the radiative transfer model. For water clouds, an effective radius of $10 \mu \mathrm{m}$ was assumed, and the liquid water content determined following Slingo (1989) analogously to the cirrus 


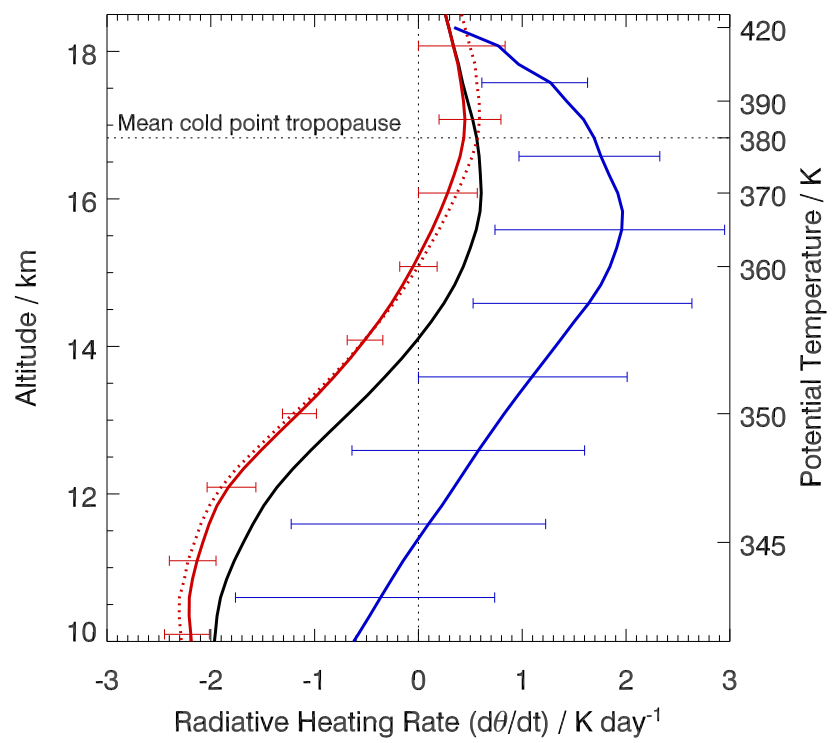

Fig. 3. Mean radiative heating rates in the tropics from more than 300000 calculations including clouds, separated for air in clouds (blue) and cloud free air (red). The horizontal bars represent the 25 th and 75 th percentiles. Also shown is a heating rate profile assuming clear sky (dotted red). The black line represents the full sky heating rates, i.e. the heating rates in clouds and cloud free air weighted with their altitude dependent occurrence frequencies.

case. The heating rates are only weakly dependent on particle size, because the cloud information in the data sets used here is given as optical depth, which is by far the most important factor influencing the radiative heating rate. Changing the particle size influences the heating rate in the cloud layer by a few percents only and even less outside the cloud.

At each of the 15 balloon sonde locations, full sky heating rate profiles were computed based on all 21472 cloud extinction profiles combined with randomly selected atmospheric profiles, resulting in more than 300000 calculations. For every calculation we accounted for the solar diurnal variation of the day. Mean profiles were calculated at all locations which were then averaged to provide a mean tropical heating rate profile. The heating rate variability resulting from variations in the temperature and ozone profiles and from clouds $\left(\sigma_{T, \mathrm{O}_{3}}\right.$,clouds $)$ was estimated based on calculations at the SHADOZ network locations, where simultaneously measured temperature and ozone profiles were available. The variability from water vapor $\left(\sigma_{\mathrm{H}_{2} \mathrm{O}}\right)$ was estimated from the 15 profiles measured at San Cristóbal, under the assumption that the variability in water vapor is uncorrelated with the variability in temperature, ozone and clouds.

$\sigma_{\text {tot }}^{2}=\sigma_{T, \mathrm{O}_{3}, \text { clouds }}^{2}+\sigma_{\mathrm{H}_{2} \mathrm{O}}^{2}$

The radiative calculations have been evaluated to compute separate heating rate profiles for air in clouds and cloud free air. The heating rate profile for air in clouds was calculated

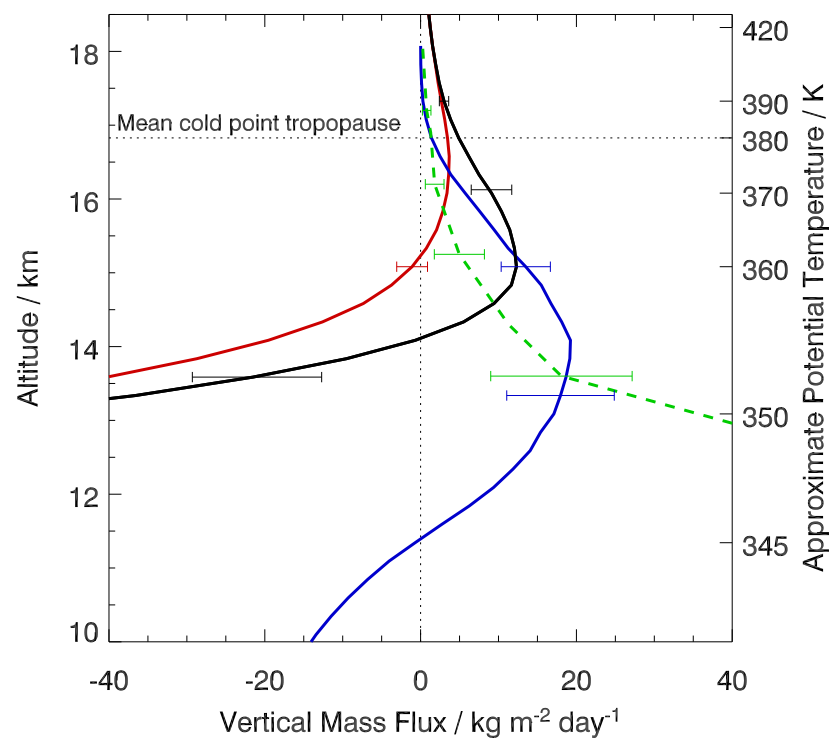

Fig. 4. Mean tropical radiatively driven vertical mass fluxes in cloud free air (red) and in clouds (blue) derived from mean radiative heating rates, weighted with their altitude dependent occurrence frequencies. The black line shows the full sky radiative mass flux, i.e. the sum of the two other profiles. The green dashed curve represents mean tropical convective mass fluxes estimated from high resolution satellite images (Gettelman et al., 2002). The horizontal lines are estimated uncertainties.

based on all those parts of the vertical profiles with cloud particles present. The calculation of the heating rate profile for cloud free air was based on all parts of the vertical profiles where no cloud particles were present (i.e., the parts of the profile above and below clouds, or the complete profile in clear sky situations where no clouds were present at all).

A series of additional calculations was performed to test the robustness of the results: For a subset of the data, the atmospheric and cloud extinction profiles have been combined based on potential temperature instead of geometrical altitude. The resulting heating rates profiles did not differ substantially from those computed on geometrical altitudes. Various calculations with mean atmospheric profiles have been performed. As discussed in Sect. 3.1, the results indeed show that one single mean profile would be sufficient to compute the tropical zonal mean radiative heating rate profile in the clear sky case. This is not true for clouds. The extinction profiles have to be combined one by one with atmospheric profiles. Altogether, the results from the radiative calculations presented here are very robust. The following sections discuss only the results based on individual atmospheric and cloud profiles with altitude as vertical coordinate. 


\section{Results and discussion}

Mean tropical profiles of radiative heating rates are depicted in Fig. 3. The figure shows mean radiative heating rates in clouds (blue) and in cloud free air (red). The horizontal bars represent the 25th and 75th percentiles, visualizing the effect of variations in temperature, ozone, water vapor and cloud properties. The red dotted line represents the mean tropic clear sky profile, (i.e. assuming no clouds at all. In contrast, the red line is for "cloud free air", which also includes air above or below clouds). The difference to the mean cloud free profile is small. This means that the influence of clouds on the mean radiative heating rates outside of clouds is small. The full sky profile (black) is the mean heating rate profile from cloudy and cloud free air weighted with their altitude dependent occurrence frequencies. In cloud free air, radiative cooling prevails below $15 \mathrm{~km}$ or $360 \mathrm{~K}$ potential temperature, but radiative heating prevails above. The radiative heating peaks at $0.5 \mathrm{~K}$ potential temperature per day around the mean cold point tropopause $(380 \mathrm{~K})$ and decreases again slightly with increasing altitude. The mean heating rate inside of clouds (blue) shows its transition from cooling to heating at $11.5 \mathrm{~km}$ or $345 \mathrm{~K}$ potential temperature. The horizontal bars indicate a substantially larger variability inside clouds compared to cloud free air. In the upper troposphere, the mean radiative heating inside clouds reaches $2 \mathrm{~K}_{\text {day }}{ }^{-1}$ and decreases with increasing altitude, approaching clear sky values at about $18 \mathrm{~km}$. Several interesting features can be deduced from Fig. 3.

First, air experiences radiative cooling in clear sky below $15 \mathrm{~km}$. Outflow air of convection therefore subsides again as soon as it is free of cloud particles (i.e., after they have sedimented out or evaporated when mixed into a subsaturated environment). As the outflow detrains from convection, it is usually saturated with respect to ice. Due to the subsidence in clear sky, however, the air warms and relative humidity decreases. With typical cooling rates of $1-2 \mathrm{Kday}^{-1}$, the air masses subside so rapidly that a renewed formation of a cloud becomes impossible after a subsidence time $t_{s}$ corresponding to only a few days. This means that the processes occurring in the first days after detrainment from convection are decisive for the further fate of air parcels with respect to TST.

Second, in the range of altitude between 12 and $15 \mathrm{~km}$, air typically experiences radiative cooling in clear sky, whereas it is heated in clouds. In principle, air can therefore be recycled in this altitude range, ascending in clouds and descending in clear sky. However, such an oscillation will be limited because of the short subsidence time $t_{s}$ mentioned above. Therefore air masses will preferentially be saturated or heavily subsaturated in clear sky. This implies a bimodal water vapor distribution as observed in the tropical upper troposphere (Zhang et al., 2003).

Third, the heating rate variability is high in clouds, because it depends strongly on the structure of the vertical ex- tinction profile. The heating rate in a thin high altitude cirrus for instance is positive in otherwise clear sky conditions, but close to zero or even negative in the case of an underlying high convective cloud (Ramaswamy and Ramanathan, 1989; Hartmann et al., 2001). It can be expected that an air parcel experiences different heating rates such that the temporal mean heating rate lies close to the mean.

Forth, the mean radiative heating rates in clouds amount to about $1.5 \mathrm{~K} \mathrm{day}^{-1}$ between 350 and $370 \mathrm{~K}$ potential temperature $(13$ and $16 \mathrm{~km})$. It follows that outflow from deep convection reaching $350 \mathrm{~K}$ can be transported into the vicinity of the cold point tropopause in approximately two weeks if it stays inside cirrus clouds for most of the time. This is faster by about a factor of 5 than thought previously assuming clear sky conditions.

Figure 4 depicts mean vertical radiative mass flux profiles for the radiative heating rate profiles shown in Fig. 3, weighted with their altitude dependent occurrence frequencies. Therefore the magnitude of the upwelling mass flux inside clouds can be directly compared with that outside clouds. The horizontal bars represent estimated uncertainties including measurement errors from the balloon sonde measurements and sampling uncertainties. The dashed green curve in Fig. 4 represents estimated mean tropical convective mass fluxes derived from an analysis of high resolution satellite images (Gettelman et al., 2002).

Figure 4 shows a substantial amount of upwelling air masses due to cirrus cloud lofting between 12 and $16 \mathrm{~km}$ (blue curve). Above $16 \mathrm{~km}$, upwelling in clear sky becomes more important than in cirrus clouds. At $17 \mathrm{~km}$, the mean altitude of the cold point tropopause, the upwelling takes predominantly place in clear sky. However, as UTTCs are extremely thin, they are not included in the LITE cloud data. Part of the upwelling near the tropopause could occur in these clouds at approximately the same rate as in clear sky, because UTTCs have only a small influence on radiative heating rates. The mass flux in the Brewer-Dobson circulation, transporting air into the upper stratosphere amounts to 1$2 \mathrm{~kg} \mathrm{~m}^{-2}$ day $^{-1}$. It is obvious from Fig. 4 that a combination of cloud lofting and clear sky upwelling is able to transport the air without the influence of deep convection from approximately $345-350 \mathrm{~K}$ into the stratosphere. The full sky radiatively driven mass flux (black curve) is negative up to $14 \mathrm{~km}$ altitude $(355 \mathrm{~K})$, which means that radiative processes as a whole lead to subsidence here. It must be concluded that convection is balancing this subsidence. Indeed, estimates of convective mass fluxes broadly support this conclusion (e.g., Gettelman et al., 2002; Kupper et al., 2004). The convective mass fluxes based on Gettelman et al. (2002) are shown in Fig. 4. Below $350 \mathrm{~K}$ potential temperature, the convective mass flux exceeds radiatively driven upwelling in clouds. Between 350 and $360 \mathrm{~K}$, radiatively driven upwelling in clouds becomes more important than convective transport. Above, radiative processes as a whole dominate the upwelling. 


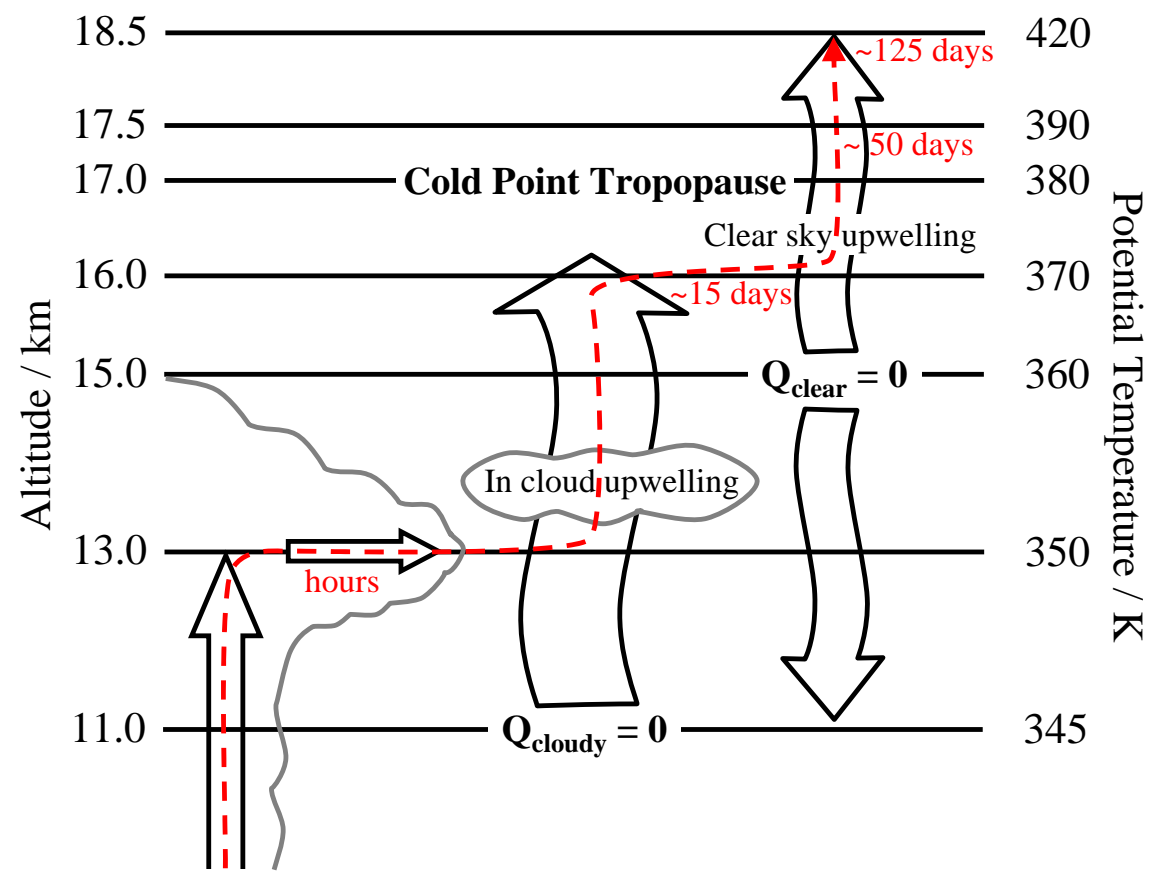

Fig. 5. Schematic of troposphere-to-stratosphere transport pathway. Left: Deep convection of moderate strength up to about $350 \mathrm{~K}$. Center: In-cloud upwelling to $370 \mathrm{~K}$. Right: Upwelling in clear sky or in optically in optically very thin cloud through the cold point tropopause into the lower stratosphere. Red numbers indicate typical transport times from the boundary layer to different levels.

\section{Conclusions}

Based on the results presented in the previous section, we conclude that the following pathway for TST, outlined in Fig. 5, is plausible. Deep convection transports air from the boundary layer to approximately $13 \mathrm{~km}(350 \mathrm{~K})$ within minutes to hours. Part of the outflow remains in cirrus clouds and is radiatively heated and lifted further.

Assuming typical mean heating rates of $1.5 \mathrm{~K} \mathrm{day}^{-1}$ (Fig. 3), air reaches $370 \mathrm{~K}$ potential temperature after about 15 days, if it stays inside cirrus clouds for most of the time. At this altitude, upwelling in clear sky becomes about as important as in cirrus clouds (Fig. 4). Air will therefore typically ascend at a slower rate than lower down. The mean full sky heating rate amounts to $0.6 \mathrm{~K} \mathrm{day}^{-1}$ between 370 and $390 \mathrm{~K}$ and then decreases to $0.4 \mathrm{~K}_{\text {day }^{-1}}$ at $420 \mathrm{~K}$. From this we estimate total transport times of 50 and 125 days from the boundary layer to 390 and $420 \mathrm{~K}$, respectively. These values agree well with the transport times derived from tracer measurements, namely $60 \pm 20$ days and $110 \pm 30$ days on 390 and $420 \mathrm{~K}$, respectively (Boering et al., 1994; Andrews et al., 1999).

The mass flux involved in the proposed transport mechanism is large enough to supply the lower stratosphere with sufficient air to feed the Brewer-Dobson circulation. It therefore eliminates the need for convective overshooting to occur frequently. Moreover, the apparent discrepancy between observations and theory disappears.
The level of zero clear sky radiative heating $\left(Q_{\text {clear }}=0\right)$, located at $15 \mathrm{~km}$, is generally regarded as a barrier for TST which has to be overcome by convection. Our results however demonstrate that outflow from convection reaching about $13 \mathrm{~km}$ can be lifted towards the cold point tropopause due to cloud lofting. Therefore, the $Q_{\text {clear }}=0$ level is not a barrier for upwelling outside of convection.

In summary, our results give strong evidence that cirrus cloud lofting is a key element for understanding tropical TST. However, it should be noted that further work is needed to corroborate this finding: First, it is difficult to deduce pathways of individual air parcels from the cloud data and derived radiative heating rates. The insights may be obtained from trajectory studies similar to that of Jensen and Pfister (2004) including cloud-radiation interactions. Second, cloud-resolving model studies of cloud lofting will be useful to investigate in detail how the radiative heating affects clouds of different spatial extent and specifically how it affects their lifetime. Finally, direct observation of cloud lofting could provide better evidence. This is, however, not an easy task, as cloud lofting is a relatively slow diabatic process, masked by stronger adiabatic processes, mostly from waves.

Acknowledgements. ISCCP and LITE data were obtained from the NASA Langley Research Center Atmospheric Sciences Data Center. SHADOZ data were provided through the database available at http://croc.gsfc.nasa.gov/shadoz/. UKMO temperature 
data and NOAA/NCDC radiosonde data were provided through the SPARC Data Center at http://www.sparc.sunysb.edu/. T. Corti is supported by the Swiss Federal Office for Education and Science as part of TROCCINOX and SCOUT-O3. Q. Fu is supported by NASA Grants NNG04GM23G and NNG05GA19G.

Edited by: B. Kärcher

\section{References}

Ackerman, T. P., Liou, K. N., Valero, F. P. J., and Pfister, L.: Heating Rates in Tropical Anvils, J. Atmos. Sci., 45, 1606-1623, 1988.

Andrews, A. E., Boering, K. A., Daube, B. C., Wofsy, S. C., Hintsa, E. J., Weinstock, E. M., and Bui, T. P.: Empirical age spectra for the lower tropical stratosphere from in situ observations of CO2: Implications for stratospheric transport, J. Geophys. Res.Atmos., 104, 26 581-26 595, 1999.

Boering, K. A., Daube, B. C., Wofsy, S. C., Loewenstein, M., Podolske, J. R., and Keim, E. R.: Tracer-Tracer Relationships and Lower Stratospheric Dynamics - CO2 and N2O Correlations During Spade, Geophys. Res. Lett., 21, 2567-2570, 1994.

Chepfer, H., Pelon, J., Brogniez, G., Flamant, C., Trouillet, V., and Flamant, P. H.: Impact of cirrus cloud ice crystal shape and size on multiple scattering effects: application to spaceborne and airborne backscatter lidar measurements during LITE mission and E LITE campaign, Geophys. Res. Lett., 26, 2203-2206, 1999.

Comstock, J. M., Ackerman, T. P., and Mace, G. G.: Ground-based lidar and radar remote sensing of tropical cirrus clouds at Nauru Island: Cloud statistics and radiative impacts, J. Geophys. Res.Atmos., 107, 4714, doi:10.1029/2002JD002203, 2002.

Corti, T., Luo, B. P., Peter, T., Vomel, H., and Fu, Q.: Mean radiative energy balance and vertical mass fluxes in the equatorial upper troposphere and lower stratosphere, Geophys. Res. Lett., 32, L06 802, 2005.

Folkins, I. and Martin, R. V.: The vertical structure of tropical convection and its impact on the budgets of water vapor and ozone, J. Atmos. Sci., 62, 1560-1573, 2005.

Folkins, I., Oltmans, S. J., and Thompson, A. M.: Tropical convective outflow and near surface equivalent potential temperatures, Geophys. Res. Lett., 27, 2549-2552, 2000.

$\mathrm{Fu}$, Q. and Liou, K. N.: On the Correlated K-Distribution Method for Radiative-Transfer in Nonhomogeneous Atmospheres, J. Atmos. Sci., 49, 2139-2156, 1992.

Fu, Q. and Liou, K. N.: Parameterization of the Radiative Properties of Cirrus Clouds, J. Atmos. Sci., 50, 2008-2025, 1993.

Fu, Q., Yang, P., and Sun, W. B.: An accurate parameterization of the infrared radiative properties of cirrus clouds for climate models, J. Climate, 11, 2223-2237, 1998.

$\mathrm{Fu}, \mathrm{Q}$. A.: An accurate parameterization of the solar radiative properties of cirrus clouds for climate models, J. Climate, 9, 20582082, 1996.

Gettelman, A., Salby, M. L., and Sassi, F.: Distribution and influence of convection in the tropical tropopause region, J. Geophys. Res.-Atmos., 107, 4080, doi:10.1029/2001JD001048, 2002.

Gettelman, A., Forster, P. M. D., Fujiwara, M., Fu, Q., Vomel, H., Gohar, L. K., Johanson, C., and Ammerman, M.: Radiation balance of the tropical tropopause layer, J. Geophys. Res.-Atmos., 109, D07 103, doi:10.1029/2003JD004190, 2004.
Hartmann, D. L., Holton, J. R., and Fu, Q.: The heat balance of the tropical tropopause, cirrus, and stratospheric dehydration, Geophys. Res. Lett., 28, 1969-1972, 2001.

Haynes, P. H., Marks, C. J., McIntyre, M. E., Shepherd, T. G., and Shine, K. P.: On the Downward Control of Extratropical Diabatic Circulations by Eddy-Induced Mean Zonal Forces, J. Atmos. Sci., 48, 651-679, 1991.

Holton, J. R., Haynes, P. H., McIntyre, M. E., Douglass, A. R., Rood, R. B., and Pfister, L.: Stratosphere-Troposphere Exchange, Rev. Geophys., 33, 403-439, 1995.

Jensen, E. and Pfister, L.: Transport and freeze-drying in the tropical tropopause layer, J. Geophys. Res.-Atmos., 109, D02 207, doi:10.1029/2003JD004022, 2004.

Kelly, K. K., Proffitt, M. H., Chan, K. R., Loewenstein, M., Podolske, J. R., Strahan, S. E., Wilson, J. C., and Kley, D.: Water-Vapor and Cloud Water Measurements over Darwin During the Step 1987 Tropical Mission, J. Geophys. Res.-Atmos., 98, 8713-8723, 1993.

Kupper, C., Thuburn, J., Craig, G. C., and Birner, T.: Mass and water transport into the tropical stratosphere: A cloudresolving simulation, J. Geophys. Res.-Atmos., 109, D10 111, doi:10.1029/2004JD004541, 2004.

Lilly, D. K.: Cirrus Outflow Dynamics, J. Atmos. Sci., 45, 15941605, 1988.

Liou, K.: Radiation and Cloud Processes in the Atmosphere, Oxford University Press, 1992.

Luo, B. P., Peter, T., Fueglistaler, S., Wernli, H., Wirth, M., Kiemle, C., Flentje, H., Yushkov, V. A., Khattatov, V., Rudakov, V., Thomas, A., Borrmann, S., Toci, G., Mazzinghi, P., Beuermann, J., Schiller, C., Cairo, F., Di Donfrancesco, G., Adriani, A., Volk, C. M., Strom, J., Noone, K., Mitev, V., MacKenzie, R. A., Carslaw, K. S., Trautmann, T., Santacesaria, V., and Stefanutti, L.: Dehydration potential of ultrathin clouds at the tropical tropopause, Geophys. Res. Lett., 30, 1557, doi:10.1029/2002GL016737, 2003.

McCormick, M. P., Winker, D. M., Browell, E. V., Coakley, J. A., Gardner, C. S., Hoff, R. M., Kent, G. S., Melfi, S. H., Menzies, R. T., Platt, C. M. R., Randall, D. A., and Reagan, J. A.: Scientific Investigations Planned for the Lidar in-Space Technology Experiment (Lite), Bull. Amer. Meteorol. Soc., 74, 205-214, 1993.

McFarquhar, G. M., Heymsfield, A. J., Spinhirne, J., and Hart, B.: Thin and subvisual tropopause tropical cirrus: Observations and radiative impacts, J. Atmos. Sci., 57, 1841-1853, 2000.

Miller, S. D. and Stephens, G. L.: Multiple scattering effects in the lidar pulse stretching problem, J. Geophys. Res.-Atmos., 104, 22 205-22 219, 1999.

Peter, T., Luo, B. P., Wirth, M., Kiemle, C., Flentje, H., Yushkov, V. A., Khattatov, V., Rudakov, V., Thomas, A., Borrmann, S., Toci, G., Mazzinghi, P., Beuermann, J., Schiller, C., Cairo, F., Di Donfrancesco, G., Adriani, A., Volk, C. M., Strom, J., Noone, K., Mitev, V., MacKenzie, R. A., Carslaw, K. S., Trautmann, T., Santacesaria, V., and Stefanutti, L.: Ultrathin Tropical Tropopause Clouds (UTTCs): I. Cloud morphology and occurrence, Atmos. Chem. Phys., 3, 1083-1091, 2003, http://www.atmos-chem-phys.net/3/1083/2003/.

Plumb, R. A.: Stratospheric transport, J. Meteorol. Soc. Jpn., 80, 793-809, 2002.

Ramaswamy, V. and Ramanathan, V.: Solar Absorption by Cirrus 
Clouds and the Maintenance of the Tropical Upper Troposphere Thermal Structure, J. Atmos. Sci., 46, 2293-2310, 1989.

Rossow, W. B. and Schiffer, R. A.: Advances in understanding clouds from ISCCP, Bull. Amer. Meteorol. Soc., 80, 2261-2287, 1999.

Sherwood, S. C. and Dessler, A. E.: A model for transport across the tropical tropopause, J. Atmos. Sci., 58, 765-779, 2001.

Sherwood, S. C. and Dessler, A. E.: Convective mixing near the tropical tropopause: Insights from seasonal variations, J. Atmos. Sci., 60, 2674-2685, 2003.

Slingo, A.: A Gcm Parameterization for the Shortwave Radiative Properties of Water Clouds, J. Atmos. Sci., 46, 1419-1427, 1989.

Sobel, A. H., Nilsson, J., and Polvani, L. M.: The weak temperature gradient approximation and balanced tropical moisture waves, J. Atmos. Sci., 58, 3650-3665, 2001.

Thompson, A. M., Witte, J. C., McPeters, R. D., Oltmans, S. J., Schmidlin, F. J., Logan, J. A., Fujiwara, M., Kirchhoff, V., Posny, F., Coetzee, G. J. R., Hoegger, B., Kawakami, S., Ogawa, T., Johnson, B. J., Vomel, H., and Labow, G.: Southern Hemisphere Additional Ozonesondes (SHADOZ) 1998-2000 tropical ozone climatology - 1. Comparison with Total Ozone Mapping Spectrometer (TOMS) and ground-based measurements, J. Geophys. Res.-Atmos., 108, 8238, doi:10.1029/2001JD000967, $2003 \mathrm{a}$.
Thompson, A. M., Witte, J. C., Oltmans, S. J., Schmidlin, F. J., Logan, J. A., Fujiwara, M., Kirchhoff, V., Posny, F., Coetzee, G. J. R., Hoegger, B., Kawakami, S. J., Ogawa, T., Fortuin, J. P. F., and Kelder, H. M.: Southern Hemisphere Additional Ozonesondes (SHADOZ) 1998-2000 tropical ozone climatology - 2. Tropospheric variability and the zonal wave-one, J. Geophys. Res.Atmos., 108, 8241, doi:10.1029/2002JD002241, 2003b.

Volger, P., Liu, Z. Y., and Sugimoto, N.: Multiple scattering simulations for the Japanese space lidar project ELISE, IEEE Trans. Geosci. Remote Sensing, 40, 550-559, 2002.

Vomel, H., Oltmans, S. J., Johnson, B. J., Hasebe, F., Shiotani, M., Fujiwara, M., Nishi, N., Agama, M., Cornejo, J., Paredes, F., and Enriquez, H.: Balloon-borne observations of water vapor and ozone in the tropical upper troposphere and lower stratosphere, J. Geophys. Res.-Atmos., 107, 4210, doi:10.1029/2001JD000707, 2002.

Winker, D. M., Couch, R. H., and McCormick, M. P.: An overview of LITE: NASA's lidar in-space technology experiment, Proc. IEEE, 84, 164-180, 1996.

Zhang, C. D., Mapes, B. E., and Soden, B. J.: Bimodality in tropical water vapour, Q. J. R. Meteorol. Soc., 129, 2847-2866, 2003. 